Pacific Journal of Mathematics

THE INVARIANCE OF SYMMETRIC FUNCTIONS OF 


\title{
THE INVARIANCE OF SYMMETRIC FUNCTIONS OF SINGULAR VALUES
}

\author{
Marvin Marcus and Henryk Minc
}

Let $M_{m, n}$ denote the vector space of all $m \times n$ matrices over the complex numbers. A general problem that has been considered in many forms is the following: suppose $\mathfrak{A}$ is a subset (usually subspace) of $M_{m, n}$ and let $f$ be a scalar valued function defined on $\mathfrak{A}$. Determine the structure of the set $\mathfrak{A}_{f}$ of all linear transformations $T$ that satisfy

$$
f(T(A))=f(A) \text { for all } A \in \mathfrak{A} .
$$

The most interesting choices for $f$ are the classical invariants such as rank $[3,4,7]$ determinant $[1,2,3,5,10]$ and more general symmetric functions of the characteristic roots $[6,8]$. In case $\mathfrak{A}$ is the set of $n$-square real skew-symmetric matrices $(m=n)$ and $f(A)$ is the Hilbert norm of $A$ then Morita [9] proved the following interesting result: $\mathfrak{A}_{\text {, }}$ consists of transformations $T$ of the form

$$
\begin{aligned}
& T(A)=U^{\prime} A U \text { for } n \neq 4, \\
& T(A)=U^{\prime} A U \text { or } T(A)=U^{\prime} A^{+} U \text { for } n=4
\end{aligned}
$$

where $U$ is a fixed real orthogonal matrix and $A^{+}$is the matrix obtained from $A$ by interchanging its $(1,4)$ and $(2,3)$ elements.

Recall that the Hilbert norm of $A$ is just the largest singular value of $A$ (i.e., the largest characteristic root of the nonnegative Hermitian square root of $A^{*} A$ ).

In the present paper we determine $\mathfrak{A}_{f}$ when $\mathfrak{A}$ is all of $M_{m, n}$ and $f$ is some particular elementary symmetric function of the squares of the singular values. We first introduce a bit of notation to make this statement precise. If $A \in M_{n, n}$ then $\lambda(A)=\left(\lambda_{1}(A), \cdots, \lambda_{n}(A)\right)$ will denote the $n$-tuple of characteristic roots of $A$ in some order. The $r$ th elementary symmetric function of the numbers $\lambda(A)$ will be denoted by $E_{r}[\lambda(A)]$; this is, of course, the same as the sum of all $r$-square principal subdeterminants of $A$. We also denote by $\rho(A)$ the rank of $A$.

Theorem. A linear transformation $T$ of the space $M_{m, n}$ leaves invariant the rth elementary symmetric function of the squares of the singular values of each $A \in M_{m, n}$, for some fixed $r, 1<r \leqq n$, if and only if there exist unitary matrices $U$ and $V$ in $M_{m, m}$ and $M_{n, n}$ respectively such that

Received January 16,1961 . The work of the first author was supported in part by the the Office of Naval Research. 


$$
\begin{aligned}
& T(A)=U A V \text { if } m \neq n \text { and } \\
& T(A)=U A V \text { or } T(A)=U A^{\prime} V \text { if } m=n .
\end{aligned}
$$

The sufficiency of (2) and (3) is clear and we prove the necessity in a sequence of lemmas some of which may be of interest in themselves. Assume without loss of generality that $m \geqq n$.

LEMma 1. Let $A, B \in M_{m, n}$ and let $\varphi_{B}(x)=E_{r}\left[\lambda\left((x A+B)^{*}(x A+B)\right)\right]$ where $x$ is a real indeterminate. Then

$$
\operatorname{deg} \varphi_{B}(x) \leqq 2 \text { for all } B \in M_{m, n}
$$

if and only if

$$
\rho(A) \leqq 1
$$

Proof. We first remark that $\varphi_{B}(x)$ is actually a polynomial in $x$ since it is the sum of all $\left(\begin{array}{l}n \\ r\end{array}\right) \quad r$-square principal subdeterminants of $(x A+B)^{*}(x A+B)$. The matrix $A$ can be written, by a slight extension of the polar factorization theorem to rectangular matrices, in the form $A=U H$ where $H$ is $n$-square hermitian positive semi-definite and $U \in M_{m, n}$ satisfies $U^{*} U=I_{n}$, the $n$-square identity matrix. Then

$$
\begin{aligned}
\varphi_{B}(x) & =E_{r}\left[\lambda\left((x U H+B)^{*}(x U H+B)\right)\right] \\
& =E_{r}\left[\lambda\left(\left(x H+U^{*} B\right)^{*}\left(x H+U^{*} B\right)\right)\right] .
\end{aligned}
$$

Now let $H=V^{*} D V$ where $V$ is unitary and $D$ is diagonal. Then

$$
\begin{aligned}
\varphi_{B}(x) & =E_{r}\left[\lambda\left(V^{*}\left(x D+V U^{*} B V^{*}\right)^{*} V V^{*}\left(x D+V U^{*} B V^{*}\right) V\right)\right] \\
& =E_{r}\left[\lambda\left(\left(x D+B_{1}\right)^{*}\left(x D+B_{1}\right)\right)\right]
\end{aligned}
$$

where $B_{1}=V U^{*} B V^{*}$. Now suppose $\rho(A)=\rho(D)=1$. Then $D$ has exactly one nonzero entry which we may clearly assume to be in the $(1,1)$ position. It follows that $\left(x D+B_{1}\right)^{*}\left(x D+B_{1}\right)$ has a quadratic polynomial in $x$ in the $(1,1)$ position, first degree polynomials in the other first row and first column positions and constants elsewhere. Therefore, every principal subdeterminant of this matrix is a polynomial in $x$ of degree at most 2.

On the other hand, if (4) holds then in particular for $B=0$

$$
\varphi_{0}(x)=E_{r}\left[\lambda\left(x^{2} D^{*} D\right)\right]
$$

and $\operatorname{deg} \varphi_{0}(x) \leqq 2$; this implies that the diagonal matrix $D^{*} D$ can have at most one nonzero entry. But then $1 \geqq \rho\left(D^{*} D\right)=\rho(D)=\rho(\mathrm{A})$.

LEMMA 2. Let $f\left(t_{1}, \cdots, t_{n}\right)$ be a monotone strictly increasing function of each $t_{j}$ for $t_{j}>0$. If $T$ is a linear map of $M_{m, n}$ into itself satisfying 


$$
f\left(\lambda\left(A^{*} A\right)\right)=f\left(\lambda\left((T(A))^{*} T(A)\right)\right), \quad A \in M_{m, n}
$$

then $T$ is nonsingular.

Proof. Suppose $T(A)=0$. Then

$$
\begin{aligned}
f\left(\lambda\left(X^{*} X\right)\right) & =f\left(\lambda\left((T(X))^{*} T(X)\right)\right) \\
& =f\left(\lambda\left((T(A+X))^{*} T(A+X)\right)\right) \\
& =f\left(\lambda\left((A+X)^{*}(A+X)\right)\right) .
\end{aligned}
$$

Let $A=U H$ where $U^{*} U=I_{n}$ and $H$ is nonnegative Hermitian. Then taking $H=V^{*} D V$ where $D$ is diagonal and $V$ is unitary we find as in Lemma 1 that

$$
f\left(\lambda\left(X^{*} X\right)\right)=f\left(\lambda\left((D+Y)^{*}(D+Y)\right)\right),
$$

$Y=V U^{*} X V^{*}$. Now as $X$ runs over $M_{m, n} Y$ runs over $M_{n, n}$ and moreover

$$
\lambda\left(X^{*} X\right)=\lambda\left(V^{*} Y^{*} V U^{*} U V^{*} Y V\right)=\lambda\left(Y^{*} Y\right) \text {. }
$$

Hence

$$
f\left(\lambda\left(Y^{*} Y\right)\right)=f\left(\lambda\left((D+Y)^{*}(D+Y)\right)\right)
$$

for all $Y \in M_{n, n}$. Let $Y$ be a real diagonal matrix with diagonal elements $y_{1}, \cdots, y_{n}$. Then if $D$ has diagonal elements $d_{1}, \cdots, d_{n}$ we conclude from (6) that

$$
f\left(y_{1}^{2}, \cdots, y_{n}^{2}\right)=f\left(d_{1}^{2}+y_{1}^{2}, \cdots, d_{n}^{2}+y_{n}^{2}\right) .
$$

Thus $D=0, A=0$ and $T$ is nonsingular.

We remark at this point that the elementary symmetric functions satisfy the conditions of Lemma 2 and hence the $T$ of the theorem is nonsingular.

Lemma 3. If $\rho(A)=1$ then $\rho(T(A))=1$.

Proof. If $\rho(A)=1$ then, by Lemma $1, \operatorname{deg} \varphi_{B}(x) \leqq 2$. Now

$$
\begin{aligned}
\varphi_{B}(x) & =E_{r}\left[\lambda\left((x A+B)^{*}(x A+B)\right)\right] \\
& =E_{r}\left[\lambda\left((T(x A+B))^{*} T(x A+B)\right)\right] \\
& =E_{r}\left[\lambda\left((x T(A)+T(B))^{*}(x T(A)+T(B))\right)\right] .
\end{aligned}
$$

By Lemma $2 T$ is nonsingular so $T(B)$ ranges over $M_{m, n}$ as $B$ does. Hence, by Lemma $1, \rho(T(A)) \leqq 1$. But $T(A) \neq 0$ since $\rho(A)=1$. Thus $\rho(T(A))=1$.

At this point we invoke [7: p. 1219] that tells us that a linear transformation on $M_{m, n}$ which preserves rank 1 has the desired form: 


$$
T(A)=U A V \text { for all } A \in M_{m, n}
$$

or

$$
T(A)=U A^{\prime} V \text { for all } A \in M_{m, n},
$$

where $U$ and $V$ are nonsingular $m$-square and $n$-square matrices respectively and the second eventuality occurs only if $m=n$. The proof of the theorem will be complete if we show

Lemma 4. $U$ and $V$ may be chosen to be unitary.

Proof. We show this when $T$ has the form (2); if $T$ has the form (3) the argument is essentially the same. Let $V=H P$ and $U=Q K$ where $H$ and $K$ are positive definite Hermitian and $P$ and $Q$ are unitary. Then

$$
\begin{aligned}
E_{r}\left[\lambda\left(A^{*} A\right)\right] & =E_{r}\left[\lambda\left((U A V)^{*}(U A V)\right)\right] \\
& =E_{r}\left[\lambda\left(V^{*} A^{*} U^{*} U A V\right)\right] \\
& =E_{r}\left[\lambda\left(P^{*} H A^{*} K^{2} A H P\right)\right] \\
& =E_{r}\left[\lambda\left(H A^{*} K^{2} A H\right)\right] \\
& =E_{r}\left[\lambda\left(H^{2} A^{*} K^{2} A\right)\right]
\end{aligned}
$$

for all $A$. Let $H=X D X^{*}, K=Y G Y^{*}, X$ and $Y$ unitary, $D$ and $G$ diagonal matrices with main diagonals $d_{1}, \cdots, d_{n}$ and $g_{1}, \cdots, g_{n}$ respectively. Then

$$
\begin{aligned}
E_{r}\left[\lambda\left(A^{*} A\right)\right] & =E_{r}\left[\lambda\left(X D^{2} X^{*} A^{*} Y G^{2} Y^{*} A\right)\right] \\
& =E_{r}\left[\lambda\left(D^{2} B^{*} G^{2} B\right)\right]
\end{aligned}
$$

where $B=Y^{*} A X$. Now

$$
\lambda\left(A^{*} A\right)=\lambda\left(X B^{*} Y^{*} Y B X^{*}\right)=\lambda\left(B^{*} B\right)
$$

and hence

$$
\left.\left.E_{r}\left[\lambda\left(B^{*} B\right)\right]=E_{r}\right] \lambda\left(D^{2} B^{*} G^{2} B\right)\right]
$$

for all $B$. Choose $B$ as follows:

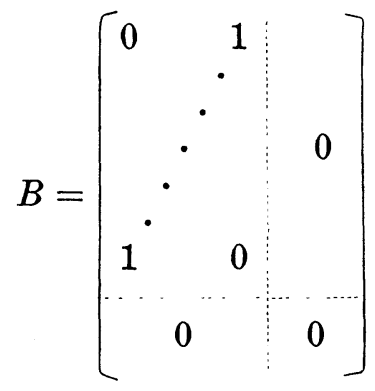


in which the upper left block is the indicated $r$-square permutation matrix. Then clearly $E_{r}\left[\lambda\left(B^{*} B\right)\right]=1$ and

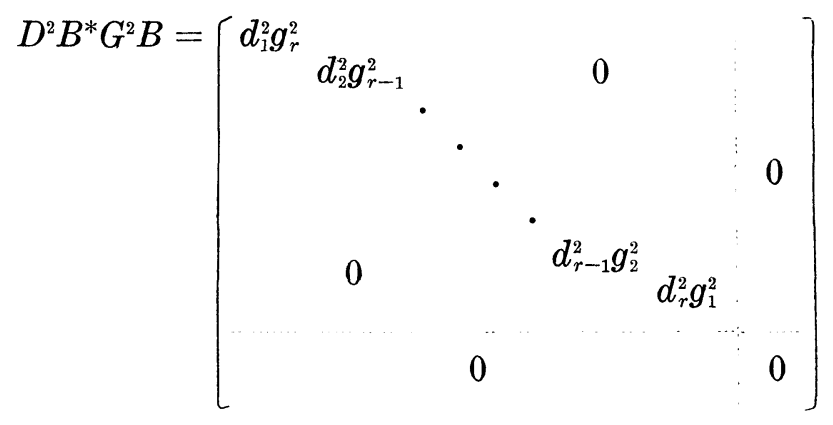

Thus

$$
1=E_{r}\left[\lambda\left(B^{*} B\right)\right]=\prod_{\jmath=1}^{r} d_{j}^{2} g_{j}^{2} .
$$

Now set $D^{2}=R D_{\sigma}^{2} R$ where $R$ is an $n$-square permutation matrix and $D_{\sigma}^{2}$ is a diagonal matrix obtained from $D^{2}$ by a permutation $\sigma$ of the diagonal elements of $D^{2}$. Then

$$
\begin{aligned}
\lambda\left(D^{2} B^{*} G^{2} B\right) & =\lambda\left(R D_{\sigma}^{2} R^{*} B^{*} G^{2} B\right) \\
& =\lambda\left(D_{\sigma}^{2}(B R)^{*} G^{2}(B R)\right) \\
& =\lambda\left(D_{\sigma}^{2} C^{*} G^{2} C\right),
\end{aligned}
$$

where $C=B R$, and

$$
\lambda\left(B^{*} B\right) \doteq \lambda\left(R^{*} B^{*} B R\right)=\lambda\left(C^{*} C\right) .
$$

Therefore

$$
E_{r}\left[\lambda\left(C^{*} C\right)\right]=E_{r}\left[\lambda\left(D_{\sigma}^{2} C^{*} G^{2} C\right)\right]
$$

for all $C$. It follows that

$$
\prod_{i=1}^{r} d_{\sigma(i)}^{2} g_{i}^{2}=1
$$

for any permutation $\sigma$ of $1, \cdots, n$. From this we conclude that

$$
d_{1}^{2}=\cdots=d_{n}^{2}=d^{2}
$$

and similarly

$$
g_{1}^{2}=\cdots=g_{n}^{2}=g^{2} .
$$

Then $G=g I, D=d I$ and $U=g Q, V=d P$, i.e. $U, V$ are scalar multiples of unitary matrices. Now, 


$$
\begin{aligned}
E_{r}\left[\lambda\left(A^{*} A\right)\right] & =E_{r}\left[\lambda\left((U A V)^{*}(U A V)\right)\right] \\
& =E_{r}\left[\lambda\left(|g|^{2} V^{*} A^{*} A V\right)\right] \\
& =E_{r}\left[\lambda\left(|g d|^{2} A^{*} A\right)\right] \\
& =|g d|^{2 r} E_{r}\left[\lambda\left(A^{*} A\right)\right] .
\end{aligned}
$$

Hence $|g d|^{2 r}=1$ and we can choose $U$ and $V$ to be $g d Q$ and $P$ which are unitary. This completes the proof.

We remark that in case $r=1 T$ does not necessarily have the form indicated in (2) and (3). For

$$
E_{1}\left[\lambda\left(A^{*} A\right)\right]=\operatorname{tr}\left(A^{*} A\right)=\sum_{(i, j)=(1,1)}^{\langle m, n)}\left|a_{i j}\right|^{2},
$$

and if $T$ is merely a unitary operator on $M_{m, n}$

$$
E_{1}\left[\lambda\left((T(A))^{*} T(A)\right)\right]=E_{1}\left[\lambda\left(A^{*} A\right)\right] .
$$

For example $T$ can be the operator that interchanges the $(1,2)$ and $(2,1)$ elements of every $A \in M_{m, n}$ (assume $m, n>2$ ) and this cannot be accomplished by any pre- and post-multipliplication as in (2) or (3).

\section{REFERENCES}

1. J. Dieudonné, Sur une généralization du groupe orthogonal à quatre variables, Archiv. d. Math., 1 (1948), 282-287.

2. G. Frobenius, Über die Darstellung der endlichen Gruppen durch lineare Substitutionen, Sitzungsberichte der Berliner Akademie, pp. 994-1015.

3. L. K. Hua, Geometries of matrices. I. Generalizations of von Staudt's theorem; Trans. Amer. Math. Soc., 57 (1945), 441-481.

4. H. G. Jacob, Coherence invariant mappings on Kronecker products, Amer. J. Math., 77 (1955), 177-189.

5. S. Kantor, Theorie der Äquivalenz von linearen $\infty^{\lambda}$ Scharen bilinearer Formen, Sitzungsberichte der Münchener Akademie, (1897), 367-381.

6. M. Marcus and R. Westwick, Linear map on skew-symmetric matrices: the invariance of elementary symmetric functions, Pacific J. Math., 10 (1960), 917-924.

7. M. Marcus and B. N. Moyls, Transformations on tensor product spaces, Pacific J. Math., 9 (1959). 1215-1221.

8. M. Marcus and R. Purves, Linear transformations on algebras of matrices: the invariance of the elementary symmetric functions, Canadian J. Math., 11 (1959), 383-396.

9. K. Morita, Schwarz's lemma in a homogeneous space of higher dimensions, Japan J. of Math., 19 (1944), 45-56.

10. I. Schur, Einige Bemerkungen zur Determinantentheorie, Sitzungsberichte der Preussischen Akademie der Wissenschaften zu Berlin, 25 (1925), 454-463.

U. S. National Bureau of Standards, Washington, D. C.

The University of Florida, Gainesville, Florida 


\section{PACIFIC JOURNAL OF MATHEMATICS}

\section{EDITORS}

Ralph S. Phillips

Stanford University

Stanford, California

M. G. Arsove

University of Washington

Seattle 5, Washington
A. L. Whiteman

University of Southern Californla

Los Angeles 7, California

Lowell J. Paige

University of California

Los Angeles 24, California

\section{ASSOCIATE EDITORS}

E. F. BECKENBACH

D. DERRY

H. L. ROYDEN

E. G. STRAUS

T. M. CHERRY

M. OHTSUKA

E. SPANIER

F. WOLF

\section{SUPPORTING INSTITUTIONS}

UNIVERSITY OF BRITISH COLUMBIA

STANFORD UNIVERSITY

CALIFORNIA INSTITUTE OF TECHNOLOGY

UNIVERSITY OF CALIFORNIA

MONTANA STATE UNIVERSITY

UNIVERSITY OF TOKYO

UNIVERSITY OF UTAH

UNIVERSITY OF NEVADA

NEW MEXICO STATE UNIVERSITY

OREGON STATE UNIVERSITY

UNIVERSITY OF OREGON

OSAKA UNIVERSITY

WASHINGTON STATE UNIVERSITY

UNIVERSITY OF WASHINGTON

UNIVERSITY OF SOUTHERN CALIFORNIA

AMERICAN MATHEMATICAL SOCIETY CALIFORNIA RESEARCH CORPORATION SPACE TECHNOLOGY LABORATORIES NAVAL ORDNANCE TEST STATION 


\section{Pacific Journal of Mathematics}

\section{Vol. 12, No. $1 \quad$ January, 1962}

Jonathan L. Alperin, Groups with finitely many automorphisms $\ldots \ldots \ldots \ldots \ldots \ldots \ldots \ldots$

Martin Arthur Arkowitz, The generalized Whitehead product ................ 7

John D. Baum, Instability and asymptoticity in toplogical dynamics . . . . . . . . . . 25

William Aaron Beyer, Hausdorff dimension of level sets of some Rademacher series .... $\quad 35$

Frank Herbert Brownell, III, A note on Cook's wave-matrix theorem . . . . . . . . . . . . . 47

Gulbank D. Chakerian, An inequality for closed space curves ................. 53

Inge Futtrup Christensen, Some further extensions of a theorem of Marcinkiewicz ....... 59

Charles Vernon Coffman, Linear differential equations on cones in Banach spaces . . . . . 69

Eckford Cohen, Arithmetical notes. III. Certain equally distributed sets of integers . . . . . 77

John Irving Derr and Angus E. Taylor, Operators of meromorphic type with multiple poles

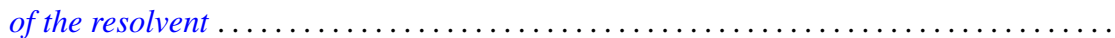

Jacob Feldman, On measurability of stochastic processes in products space .............

Robert S. Freeman, Closed extensions of the Laplace operator determined by a general class of boundary conditions, for unbounded regions ......................

Robert E. Fullerton, Geometric structure of absolute basis systems in a linear topological

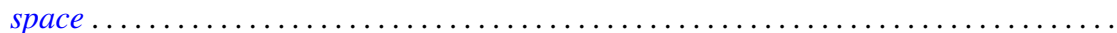

Dieter Gaier, On conformal mapping of nearly circular regions

Andrew Mattei Gleason and Hassler Whitney, The extension of linear functionals defined

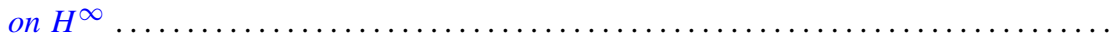

Seymour Goldberg, Closed linear operators and associated continuous linear

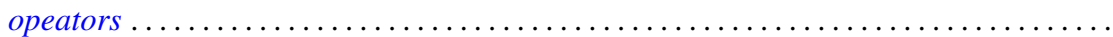

Basil Gordon, Aviezri Siegmund Fraenkel and Ernst Gabor Straus, On the determination of sets by the sets of sums of a certain order

Branko Grünbaum, The dimension of intersections of convex sets. .

Paul Daniel Hill, On the number of pure subgroups

Robert Peter Holten, Generalized Goursat problem . .

Alfred Horn, Eigenvalues of sums of Hermitian matrices ...........

Henry C. Howard, Oscillation and nonoscillation criteria for

$$
y^{\prime \prime}(x)+f(y(x)) p(x)=0
$$

Taqdir Husain, $S$-spaces and the open mapping theorem ...

Richard Eugene Isaac, Markov processes and unique stationary probability measures ...

John Rolfe Isbell, Supercomplete spaces ....................

John Rolfe Isbell, On finite-dimensional uniform spaces. II .........

N. Jacobson, A note on automorphisms of Lie algebras ..............

Antoni A. Kosinski, A theorem on families of acyclic sets and its applications

Marvin David Marcus and H. Minc, The invariance of symmetric functions of singular values...

Ralph David McWilliams, A note on weak sequential convergence.

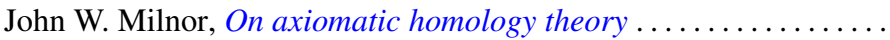

Victor Julius Mizel and Malempati Madhusudana Rao, Nonsymmetric projections in

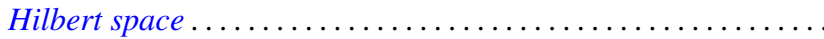

Calvin Cooper Moore, On the Frobenius reciprocity theorem for locally compact

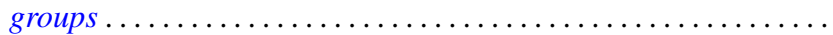

Donald J. Newman, The Gibbs phenomenon for Hausdorff means . 